Génét. Sél. Evol., 1988, 20 (1), 75-86

\title{
Chromosomal analysis of selected lines of Drosophila melanogaster with a new level of bristle canalization
}

\author{
Eva GARCÍA-VÁZQUEZ and J. RUBIO \\ Departamento de Biología Funcional (Area de Genética), \\ Facultad de Medicina, C/Julián, Clavería, s/n, 33006-Oviedo, Spain
}

\begin{abstract}
Summary
A new phenotype of extra bristles has been canalized through selection in four lines of D. melanogaster. A chromosomal analysis of these lines has been carried out. All three main chromosomes contribute with strong interactions to the increase in bristle number, and chromosome 3 has the highest contribution to this increase. Chromosome 1 and/or 2 are, instead, primarily responsible for bristle canalization in the scutum in these lines. The results are discussed in relation to a proposed genetic model for bristle determination.
\end{abstract} gaster.

Key words : canalizing selection, extra bristles, chromosomal analysis, Drosophila melano-

\section{Résumé}

Analyse chromosomique de lignées de Drosophila melanogaster présentant un changement du niveau de canalisation des soies

Un nouveau phénotype de soies surnuméraires a été obtenu par sélection canalisante dans quatre lignées de Drosophila melanogaster. Une analyse chromosomique de ces lignées a été effectuée. Les trois principaux chromosomes contribuent, avec de fortes interactions, à l'augmentation du nombre de soies, le chromosome 3 ayant la contribution la plus élevée. Les chromosomes 1 et/ou 2 sont les principaux responsables de la canalisation des soies scutellaires dans ces lignées. Les résultats sont discutés par rapport à un modèle génétique proposé pour rendre compte du déterminisme des soies.

Mots clés : sélection canalisante, soies surnuméraires, analyse chromosomique, Drosophila melanogaster.

\section{Introduction}

Scutellar and dorsocentral bristles of Drosophila melanogaster have been widely studied as a model of canalized characters. Practically all the individuals of natural populations have the normal phenotype (fig. 1), although some are not canalized and 
have extra bristles. These can be selected, and canalized lines can be obtained with extra bristles, e.g., two scutellar extra bristles (MACBEAN et al., 1972) or two dorsocentral extra bristles (GARCIA-VAzQuez \& Rubio, 1982).

NORMAL PHENOTYPE

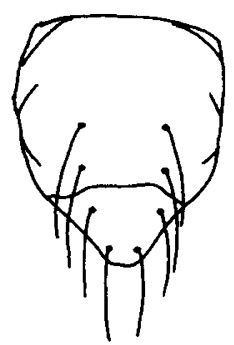

PHENOTYPE SELECTED

IN LINES SC

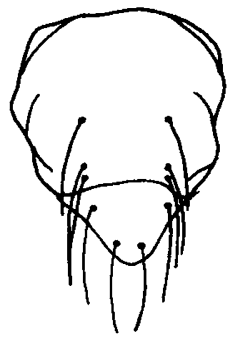

$\underline{\mathrm{pp}}$
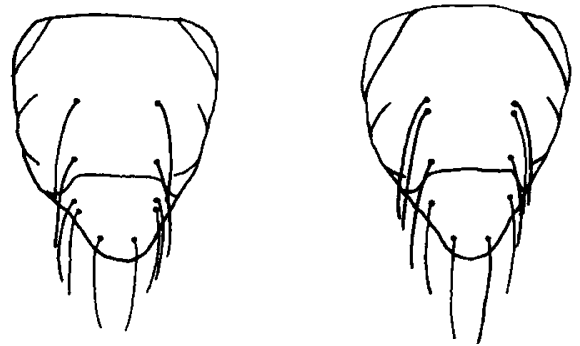

PHENOTYPE SELECTED

IN LINES ADC

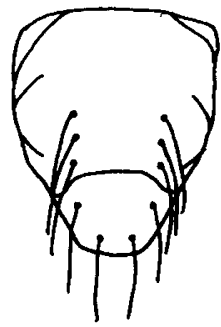

$\underline{\text { i } i}$

FIG. 1

Some phenotypes of dorsocentral and scutellar extra bristles of Drosophila melanogaster : normal phenotype canalized in wild populations (above), phenotypes selected in ADC and SC lines (middle), and other phenotypes which appeared in class 2 (below).

Some authors have proposed models to explain the genetic determination of bristles. The genetic control mechanism is different for the increase of bristle number and for the canalization of such bristles (Fraser, 1967, 1970 ; RENDEL, 1962, 1976, 1979). The action of the genes involves an increase of chaetogen, the substance that 
makes bristles (Richelle \& GHySEN, 1979). Though the amount of chaetogen increases, the regulator or canalizer action obstructs the production of one more bristle if this amount does not surpass a given threshold. This action is, at least partly, due to genes with dose-dependent properties, with negative control over major genetic systems (like the bithorax complex and the achaete-scute, Garcia-Bellido, 1981 ; Botas et al., 1982). The canalization of the normal phenotype requires that only one bristle is formed in each position, although the level of chaetogen can oscillate, because nearby cells are inhibited, preventing their differentiation as bristle forming (GHYSEN \& Richelle, 1979).

But, what genetic differences for this character are there between the populations canalized at a level close to the normal, with two extra bristles, and the normal ones ? Has selection modified the basic level of chaetogen or the canalization in each bristle position? The variability of the bristles in some cases seems to be regulated by polygenes, and not by the action of major mutants (Rubio \& Albornoz, 1982). In selection experiments to increase the number of extra bristles, both dorsocentral and scutellar, authors reported genetic variability in the three main chromosomes, with higher or lower influence of each one, according to the lines (e.g. WhrtrLe, 1969 ; Sheldon \& Milton, 1972).

Nevertheless, it has not been determined which system was modified by the genetic change produced in the lines. Is it the one that determines the quantity of chaetogen, or the one that controls the canalization, in each position of the scutum and the scutellum (anteriors and posteriors in each area), or both systems jointly ? In this work we attempt to discriminate between them, analysing which chromosomes brought the variability for each one in obtaining the response to selection.

\section{Material and methods}

The selection was made for 44 generations in four isofemale lines originating in a natural population caught in Asturias (North of Spain). In each generation, the phenotypes of 60 males and 60 females were scored, and 10 virgin couples were taken as parents from the following phenotype :

- SC : two anterior scutellar extra bristles (e.b.) ;

- ADC : two anterior dorsocentral e.b. (see fig. 1).

The evolution of the e.b. average in each line was analysed over the 44 generations. Also the distribution of the different numerical phenotypes $(0,1,2$ or more e.b.) was studied at the beginning and at the end of the selection. The size of class 2 was measured by probits, following RENDEL (1979). Finally, positional phenotypes that appeared in the selected class 2 e.b. were studied in the scutum. These phenotypes can be : $a a$ (both e.b. in anterior position), $p p$ (posteriors), ap (one anterior and the other one posterior), $i i$ (at least one e.b. is intermediate, its position can not be determined); see figure 1 . In the scutellum, extra bristles only appeared in the anterior selected position.

When the lines were canalized for the new selected phenotype, at generation 44 , the influence of the three main chromosomes in the canalization was determined. Synthetic stocks were made with one, two, or the three chromosomes of each line homozygous, with the rest of the chromosomes coming from the Oregon stock, which has a normal bristle phenotype. It has been demonstrated previously that Oregon is 
dominant over the selected lines, because all the progeny of their reciprocal crosses were normal. For this reason, stocks were not made with chromosomes heterozygous.

The intermediate line we used, which has balanced chromosomes, is the BinscySM5-TM3. Chromosome 1 is Binscy, which has the mutants Bar and yellow as markers. Chromosome 2 (SM5) has Curly. Chromosome 3 (TM3) has Stubble and Serrate. The model of crosses proposed by Kearsey \& KojIma (1967) was followed. Three independent replicates from each cross were made in each line ; 60 males' and 60 females' phenotypes were recorded in each. It was demonstrated by means of contingency $\chi^{2} s$ that significant differences do not exist among the three replicates, so their data appear grouped in the results.

Every chromosomal combination is designated by three letters, which correspond to chromosomes, $1,2,3$. Chromosomes originating in the Oregon stock are called $\mathrm{A}$; and those from the selected line are called $B$.

The lines were cultured at room temperature, in $200 \mathrm{~cm}^{3}$ glass bottles, in a medium of sugar, yeast and agar.

\section{Results}

The results are shown only for the females, because the males, which always preserve a slight sexual dimorphism, behave in the same way.

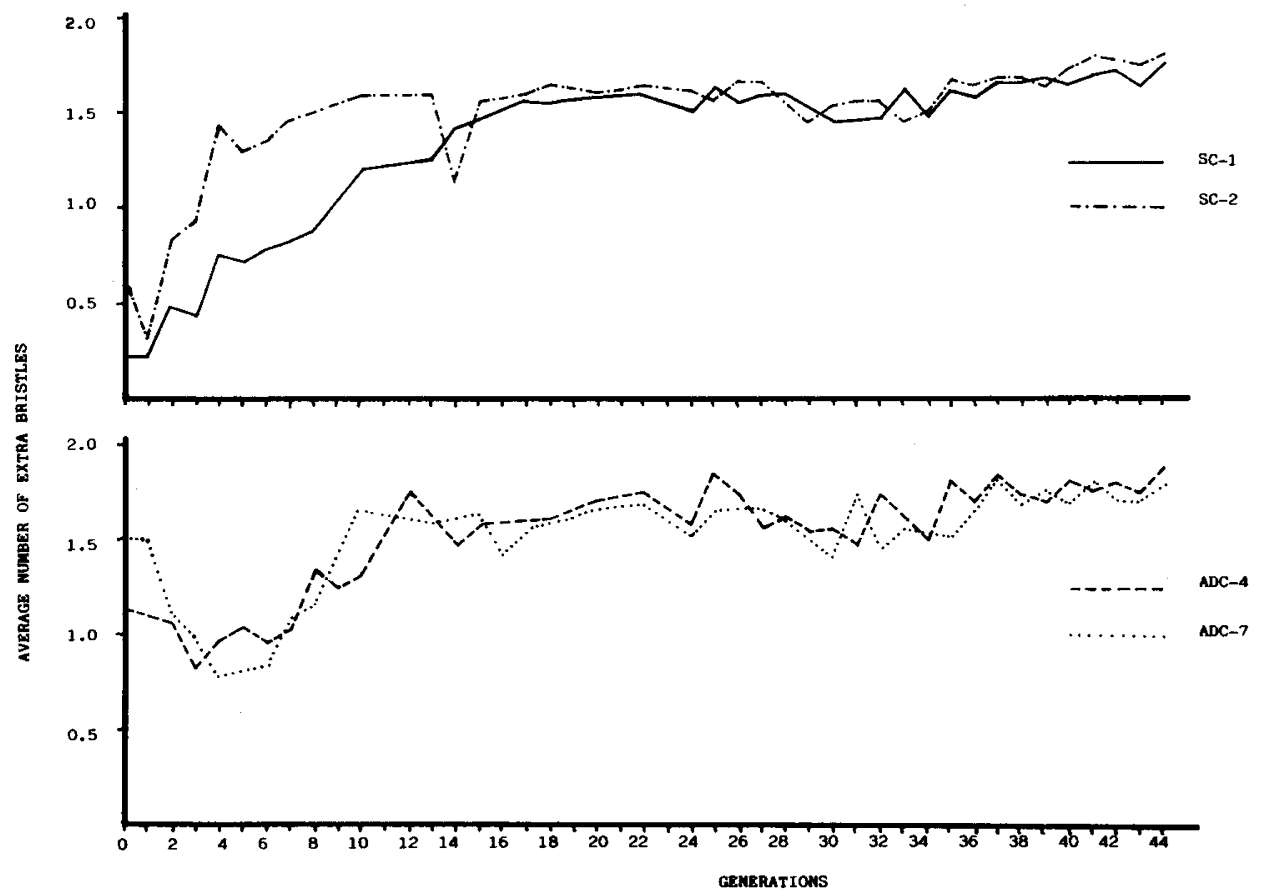

FIG. 2

Evolution of the bristle average during the 44 generations of selection: lines SC (top) and ADC (bottom). 
The response to selection is quick and constant. The extra bristle average is getting closer and closer to 2 , with a small but significant slope until the last generations (fig. 2). This rise is due to the increase of class 2 , but not to the higher ones (fig. 3). The distribution in the last generations obviously has the maximum in this class. The probits corresponding to class 2 (table 1) are big enough to affirm that the lines are canalized (RENDEL et al., 1966 ; MACBEAN et al., 1972). The distribution of bristles in the lines move into class 2 , without surpassing the threshold in spite of selection pressure for increasing the bristle number.

The position of the extra bristles was fixed and constant, which is always the selected (anterior scutellar) in the SC, and more than $90 \%$ in ADC in each generation (fig. 4). We succeeded really in canalizing a new level of extra bristles.

The contribution of every chromosome to this response was analyzed (table 2) ; $\mathrm{BBB}$ is the selected line, reconstructed after crossing with the intermediate stock; AAA is the Oregon reconstructed line, the three main chromosomes belonging to that line. The BBB average is not the same as that in every line in generation 44 , because there are fewer individuals from class 2 ; there is a slight increase of classes smaller than 2, and also of the classes higher than 2. These modifications may perhaps be attributed to the influence of the chromosome 4 in every line, which is not balanced in this experiment. It must contribute to the maintenance of homeostasis in populations, adjusting to the rest of the genotype. In any case, this decrease of the expression does not modify substantially our conclusions.

The variance analysis shows that the three chromosomes have significant influences on the increase of the average of e.b., with strong interactions among them in the four lines (table 3).

The standard test a posteriori (see table 4) arranges the distributions of chromosomal combinations according to their similarity, making statistically homogeneous groups. From the numerical point of view (distribution of individuals according to their number of e.b.), the standard test a posteriori shows that in all the lines chromosome 3 is the one that has influenced most substantially the increase in the number of e.b. ; that is to say, the greatest part of the loci, or the ones most important in production of chaetogen, are on this chromosome. Chromosomal combination AAB belongs to the same group as BBA in three of the lines ; in ADC-4 it is even higher. Chromosome 3 increased the number of extra bristles as much as the two other chromosomes together, and more in ADC-4. On the other hand, the chromosome that is second in importance for increasing bristles varies among lines. Chromosomes 1 and 2 look similar in ADC-4 ; chromosome 2 is more important in ADC-7 and SC-1 (its absence moves BAB away from the $\mathrm{BBB}$ distribution, and $\mathrm{ABB}$ is intermediate). Chromosome 1 is more important in SC-2 (ABB is further from BBB than $B A B$ is).

Up to now, we have studied the effect of every chromosome on the increase of the number of bristles, and supposedly on the increase of chaetogen. But, what about the canalization?

Apart from SC-1, which has no clear signs of decanalization but only signs of decrease of bristles, there are chromosomal combinations in the other lines that attract attention (table 2). Chromosomal combination ABB is positionaily decanalized in SC-2 : posterior dorsocentral e.b. appear. The scutellum does not decanalize in any case. 

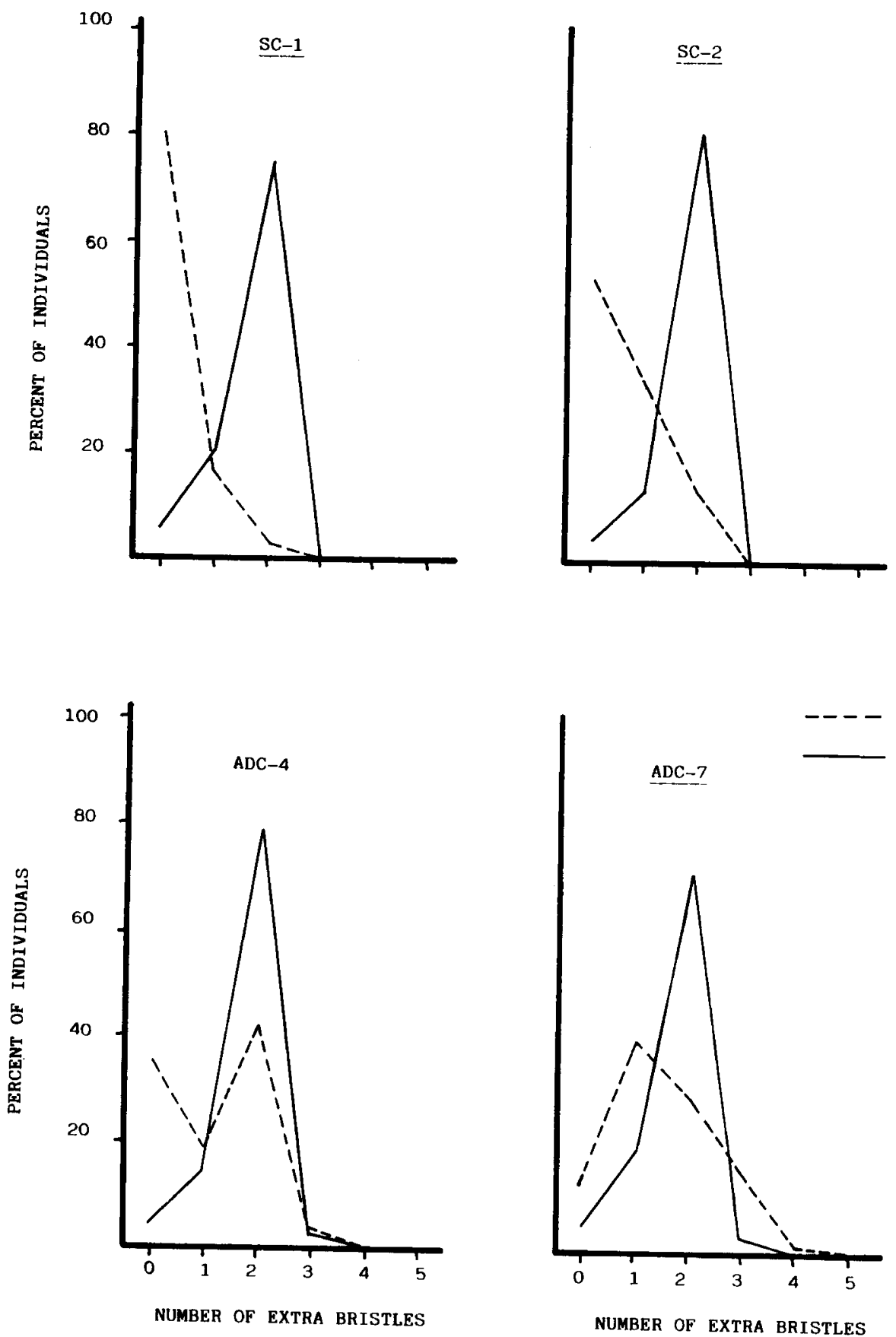

G.0

G.40-G.44

NUMBER OF EXTRA BRISTLES

Fig. 3

Frequency distribution (in percent) of flies by their number of extra bristles, in the first (G.O) and in the last (G.40-G.44, pooled) generations of selection: lines SC (top) and ADC (bottom). 
TABLE 1

Mean value of probits of class 2, for the last generations of selection (generations 38-44)

\begin{tabular}{c|c}
\hline \hline Line & Probit \\
\hline SC-1 & 5.594 \\
SC-2 & 5.745 \\
ADC-4 & 5.700 \\
ADC-7 & 5.544 \\
\hline
\end{tabular}

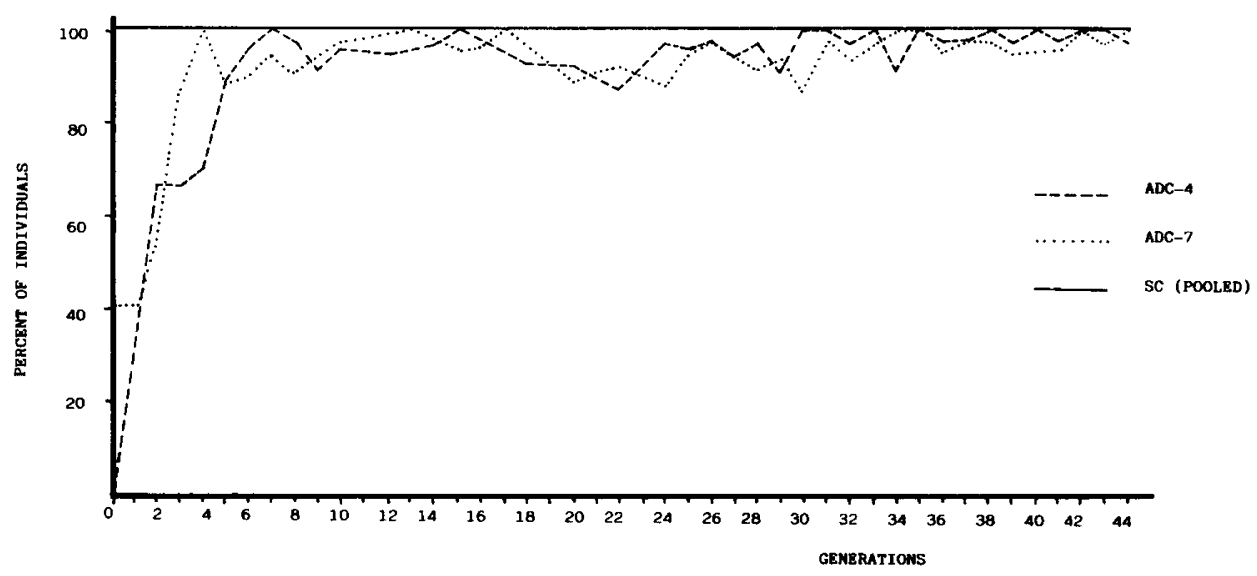

FIG. 4

Evolution of the frequency of flies with the selected pattern in class 2 extra bristles, during the 44 generations of selection.

Chromosomal combination $\mathrm{BAB}$ is also positionally decanalized in ADC-4 ; moreover, it has some individuals with more than 2 e.b. In ADC-7, BAB has some positional decanalization, and $\mathrm{ABB}$ is clearly positionally and numerically decanalized. These observations are statistically proved by positional standard test a posteriori (table 4), in which chromosomal combinations come together in homogeneous groups.

It can be inferred from them that in ADC-7 and SC-2 chromosome 1 is the most influential in controlling the canalization obtained in the scutum. In ADC-4, determining factors of canalization on chromosome 2 were selected. Chromosome 3, which has the most importance in increasing the level of chaetogen, does not seem to have fundamental genetic factors in these lines which maintain the new level of canalization, or at least they are not detected in this work. 
TABLE 2

Distribution of flies in classes of extra bristles and average number of extra bristles, in each chromosomal combination of each selection line (generation 44)

\begin{tabular}{|c|c|c|c|c|c|c|c|c|c|}
\hline Line & Classes & BBB & BBA & BAB & ABB & BAA & $\mathrm{ABA}$ & $\mathrm{AAB}$ & AAA \\
\hline \multirow{6}{*}{ SC-1 } & Class 0 & 23.9 & 85.6 & 81.7 & 57.2 & 97.8 & 98.9 & 91.1 & 100.0 \\
\hline & Class 1 & 35.6 & 11.1 & 11.7 & 27.2 & 2.2 & 1.1 & 7.8 & 0.0 \\
\hline & Class 2 sel. & 40.6 & 3.3 & 6.6 & 15.6 & 0.0 & 0.0 & 1.1 & 0.0 \\
\hline & unsel. & 0.0 & 0.0 & 0.0 & 0.0 & 0.0 & 0.0 & 0.0 & 0.0 \\
\hline & Classes $>2$ & 0.0 & 0.0 & 0.0 & 0.0 & 0.0 & 0.0 & 0.0 & 0.0 \\
\hline & Average & 1.40 & 0.17 & 0.25 & 0.58 & 0.02 & 0.01 & 0.10 & 0.00 \\
\hline \multirow{6}{*}{ SC-2 } & Class 0 & 8.9 & 87.2 & 42.2 & 61.7 & 100.0 & 100.0 & 84.4 & 98.9 \\
\hline & Class 1 & 35.0 & 10.0 & 33.3 & 24.4 & 0.0 & 0.0 & 11.7 & 1.1 \\
\hline & Class 2 sel. & 56.1 & 2.8 & 23.9 & 8.3 & 0.0 & 0.0 & 3.9 & 0.0 \\
\hline & unsel. & 0.0 & 0.0 & 0.6 & 5.6 & 0.0 & 0.0 & 0.0 & 0.0 \\
\hline & Classes $>2$ & 0.0 & 0.0 & 0.0 & 0.0 & 0.0 & 0.0 & 0.0 & 0.0 \\
\hline & Average & 1.82 & 0.16 & 0.93 & 0.52 & 0.00 & 0.00 & 0.20 & 0.01 \\
\hline \multirow{6}{*}{ ADC-4 } & Class 0 & 8.9 & 94.4 & 48.1 & 55.0 & 93.9 & 98.3 & 79.4 & 97.8 \\
\hline & Class 1 & 33.9 & 4.4 & 24.6 & 23.9 & 4.4 & 1.7 & 10.0 & 2.2 \\
\hline & Class 2 sel. & 57.2 & 1.1 & 20.0 & 19.4 & 1.7 & 0.0 & 8.9 & 0.0 \\
\hline & unsel. & 0.0 & 0.0 & 4.4 & 0.0 & 0.0 & 0.0 & 0.6 & 0.0 \\
\hline & Classes $>2$ & 0.0 & 0.0 & 2.8 & 1.7 & 0.0 & 0.0 & 1.1 & 0.0 \\
\hline & Average & 1.72 & 0.07 & 0.82 & 0.68 & 0.08 & 0.01 & 0.32 & 0.02 \\
\hline \multirow{6}{*}{ SC-1 } & Class 0 & 15.6 & 92.2 & 65.6 & 47.8 & 92.8 & 85.0 & 89.4 & 95.0 \\
\hline & Class 1 & 33.3 & 7.2 & 16.1 & 20.5 & 7.2 & 10.6 & 8.3 & 3.3 \\
\hline & Class 2 sel. & 45.0 & 0.6 & 15.0 & 15.0 & 0.0 & 4.4 & 2.2 & 0.6 \\
\hline & unsel. & 0.6 & 0.0 & 2.8 & 6.7 & 0.0 & 0.0 & 0.0 & 0.6 \\
\hline & Classes $>2$ & 5.6 & 0.0 & 0.6 & 10.0 & 0.0 & 0.0 & 0.0 & 0.6 \\
\hline & Average & 1.75 & 0.08 & 0.53 & 0.95 & 0.07 & 0.19 & 0.12 & 0.08 \\
\hline
\end{tabular}

Sel. : Selected positional phenotype ; unsel. : unselected positional phenotypes. 
TABLE 3

$F$ values and their significance, in the four variance analyses of the extra bristle average of chromosomal combinations, in each line

\begin{tabular}{l|c|c|c|c}
\hline \hline Source of variance & SC-1 & SC-2 & ADC-4 & ADC-7 \\
\hline Chromosome $1 \ldots \ldots \ldots$ & $71.79^{* * *}$ & $127.29^{* * *}$ & $138.04^{* * *}$ & $215.50^{* * *}$ \\
Chromosome $2 \ldots \ldots \ldots$ & $176.40^{* * *}$ & $49.35^{* * *}$ & $79.29^{* * *}$ & $855.68^{* * *}$ \\
Chromosome $3 \ldots \ldots \ldots$ & $245.66^{* * *}$ & $249.06^{* * *}$ & $573.34^{* * *}$ & $1556.65^{* * *}$ \\
Interaction $1-2 \ldots \ldots \ldots$ & $35.73^{* * *}$ & $14.48^{* *}$ & $14.87^{* *}$ & $14.20^{* *}$ \\
Interaction $1-3 \ldots \ldots \ldots$ & $33.08^{* * *}$ & $95.41^{* * *}$ & $103.77^{* * *}$ & $314.69^{* * *}$ \\
Interaction $2-3 \ldots \ldots \ldots$ & $2.19 \mathrm{~N} . \mathrm{S}$. & $30.36^{* * *}$ & $82.97^{* * *}$ & $664.58^{* * *}$ \\
Interaction $1-2-3 \ldots \ldots \ldots$ & $15.33^{* *}$ & $4.34 \mathrm{~N} . \mathrm{S}$. & $15.50^{* *}$ & $44.93^{* * *}$ \\
\hline
\end{tabular}

TABLE 4

Standard test a posteriori (STP), realized with the distributions of chromosomal combinations, in each line

SC-1

Numerical STP

$\underline{B B B} \underline{A B B} \underline{B A B}$ BBA AAB BAA ABA AAA

SC-2

Numerical STP

$\underline{B B B} \underline{B A B} \underline{A B B} \underline{A A B} B B A$ BAA ABA AAA

Positional STP

BBB AAB BBA BAB

ADC-4

Numerical STP

$\underline{B B B}$ BAB ABB AAB BBA BAA ABA AAA

Positional STP

BBB ABB BAA BBA AAB BAB

ADC-7

Numerical STP

$\underline{B B B}$ ABB BAB ABA AAB BBA BAA AAA

Positional STP

$\underline{A B A}$ AAB BBA BBB BAB $\underline{\text { ABB }}$

Numerical STP : it groups combinations for the distributions by their number of extra bristles.

Positional STP : it groups combinations for the distributions of class 2 by their positionnal phenotype (selected and unselected). 


\section{Discussion}

These results do not differ much from those of other authors. For example, Macbean et al. (1971) and Sheldon \& Milton (1972) attribute to chromosome 3 the most importance in increasing the number of bristles in some lines ; so do RuBio \& Albornoz (1982) for dorsocentral e.b. Others find chromosomes 1 and 2 more important (e.g. Scowcroft, 1966, in scutellars), or only one of them (FerRando et al., 1984, in dorsocentrals find chromosome 1 important in lines with dorsocentral e.b.). Every population has different variability for each chromosome to determine an increase of the chaetogen. This variability is higher for chromosome 3 in this population; or perhaps the random sampling of parents maintained a higher variability for chromosome 3 in these lines.

Following Richelle \& Ghysen (1979), the level of chaetogen increased in these lines, due to the manipulation by selection of genes distributed on all the largest chromosomes, but especially on chromosome 3. Moreover, there is a particular regulation in each position (anterior and posterior) of the scutum, that is probably due to the creation of an inhibition area around each bristle forming in the normal phenotype. Bristle formation at the anterior and posterior sites could be modified independently (RoBERTSON, 1965) ; it could be due to a different temporary determination of the chaetogen production in each site (Poodry, 1975).

We think that in these lines, genes from chromosomes 1 or/and 2 that strengthen this negative control were selected. This control inhibits new bristles in the non-selected positions (posterior dorsocentrals), because they do not appear with a higher level of chaetogen (the level of selected lines). When chromosomes 1 and/or 2 from the selected line are replaced by others from Oregon, which had an inhibitor sufficient to control a smaller level of chaetogen (it is of normal phenotype), extra bristles appear. The control is not enough, and the amount of chaetogen, which we selected mainly in genes from the chromosome 3 , is expressed.

Canalization is this control of bristle development. As we can see, these data make a clear difference between the two systems that regulate the production of bristles. One system is the canalizer, due to chromosome 1 and/or 2 . The other one is the chaetogen increasing, due to chromosome 3. Further work may be done in order to find which genes are involved in both systems.

Received March 4, 1987.

Accepted August 5, 1987.

\section{References}

Botas J., Moscoso del. Prado J., Garcia-Bellido A., 1982. Gene-dose titration analysis in the search of trans-regulatory genes in Drosophila. EMBO J., 1, 307-310.

Ferrando C., Sales M., Nuez F., 1984. Análisis cromosómico del sistema de macroquetas dorsocentrales. In : XX Jornadas de Genética Luso-Españolas, September 19-21, 1984, Junta de Castilla y León publ., Salamanca, Spain.

Fraser A.S., 1967. Variation of scutellar bristles in Drosophila. 15. Systems of modifiers. Genetics, 57, 919-934. 
FraSER A.S., 1970. Variation of scutellar bristles in Drosophila. 16. Major and minor genes. Genetics, 65, 305-309.

Garcia-Bellido A., 1981. From the gene to the pattern : chaeta differentiation. In : Lloyd C.W., ReEs D.A. (ed.), Cellular controls in differentiation, 281-301, Academic Press, London.

Garcia-VÁzquez A., Rubio J., 1982. Stabilizing selection for number and pattern of extra bristles in Drosophila melanogaster. In : LaKovaARA S. (ed.), Advances in genetics, developments and evolution of Drosophila, 343-360, Plenum Press, New York.

Ghysen A., Richelle J., 1979. Determination of sensory bristles and pattern formation in Drosophila. 2. The achaete-scute locus. Dev. Biol., 70, 438-452.

KeARSEY M.J., Kojima K., 1967. The genetic architecture of body weight and egg hatchability in D. melanogaster. Genetics, 56, 23-37.

Macbean I.T., McKenzie J.A., Parsons P.A., 1971. A pair of closely linked genes controlling high scutellar chaeta number in Drosophila. Theor. Appl. Genet., 41, 227-235.

Macbean I.T., McKenzie J.A., Parsons P.A., 1972. Selection for six scutellar chaetae in D. melanogaster. Theor. Appl. Genet., 72, 12-15.

POodRY C.A., 1975. A temporal pattern in the development of sensory bristles in Drosophila. Wilhem Roux's Arch., 178, 203.

Rendel J.M., 1962. The relationship between gene and phenotype. J. Theoret. Biol., 2, 296-308.

RENDEl J.M., 1976. Is there a gene regulating the scute locus on the third chromosome of D. melanogaster. Genetics, 83, 573-600.

Rendel J.M., 1979. Canalization and selection. In : Thompson (J.N., Jr.), Thoday J.M. (ed.), Quantitative genetic variation, 139-156, Academic Press, New York.

Rendel J.M., Sheldon B.L., Finlay D.E., 1966. Selection for canalization of the scute phenotype. Amer. Nat., 100, 13-22.

Richelle J., Ghysen A., 1979. Determination of sensory bristles and pattern formation in Drosophila. 1. A model. Dev. Biol., 70, 418-437.

RoBERTSON A., 1965. Variation in scutellar bristle number : an alternative hypothesis. Amer. Nat., 99. $19-23$.

Rubio J., Albornoz J., 1982. Supresión y adición de macroquetas dorsocentrales y escutelares en D. melanogaster. Rev. R. Acad. Cienc. Exact. Fis. Nat., LXXVI, 773-802.

Scowcroft W.R., 1966. Variation of scutellar bristles in Drosophila. 9. Chromosomal analysis of scutellar bristle selection lines. Genetics, 53, 389-402.

Sheldon B.L., Milton M.K., 1972. Studies on the scutellar bristles of D. melanogaster. 2. Longterm selection for high bristle number in the Oregon rc strain and correlated response in abdominal chaetae. Genetics, 71, 567-595.

WhitTLE J.R.S., 1969. Genetic analysis of the control of number and pattern of scutellar bristles in D. melanogaster. Genetics, 63, 167.

I.N.R.A. - C.R.R.Z.

Département de Génétique Animals BIBLIOTHĖOUE

E 78350 JOUY EN JOSAS 